\title{
Emancipação municipal e desenvolvimento local: o caso de Itapiranga
}

Paulo Ricardo Bavaresco

Professor e pesquisador da Universidade do Oeste de Santa Catarina (UNOESC/Campus São Miguel do Oeste)

Douglas Orestes Franzen

Mestrando do Programa de Pós-Graduação em História da Universidade de Passo Fundo (UPF)

Tiones Ediel Franzen

Mestrando do Programa de Pós-Graduação em Economia da Universidade Federal de Viçosa (UFV)

Recebido: 19/08/2013 Versão revisada (entregue): 19/11/2013 Aprovado: 28/11/2013

\begin{abstract}
Resumo
O objetivo neste artigo é examinar o processo de emancipação do município de Itapiranga, no extremo Oeste do Estado de Santa Catarina, ocorrido no ano de 1954, portanto, na conjuntura histórica do após-Segunda Guerra Mundial. O método utilizado é o da história comparada, com base em análise bibliográfica e documental sobre o período. A implantação de novos municípios visava estimular o desenvolvimento do interior do país, promovendo a descentralização administrativa por meio dessas entidades federativas. Os processos de emancipação de municípios, na década de 1950, são discutidos a partir da colonização "Porto Novo", que serviu de base para a formação do município de Itapiranga. Como fundamentação historiográfica aborda-se a concepção de municipalismo presente em diversas constituições brasileiras. A partir daí se analisa, então, o processo de emancipação do município de Itapiranga e a noção de desenvolvimento que se formou através da Comissão Municipal de Desenvolvimento Econômico. Como resultado, o artigo permite inferir que a emancipação de Itapiranga favoreceu um processo de desenvolvimento local que se expressa em diversos setores do município.
\end{abstract}

Palavras-chave | Descentralização administrativa; desenvolvimento local; emancipação municipal; história comparada; Itapiranga; Porto Novo.

Código JEL | O18; R10; R11.

\section{MUNICIPAL EMANCIPATION AND LOCAL DEVELOPMENT: THE CASE OF ITAPIRANGA}

\section{Abstract}

The purpose in this paper is to examine the emancipation process of the municipality of Itapiranga in the Brazilian State of Santa Catarina in 1954, during the historical conjuncture of the postwar. The method used is that of comparative history, based on bibliographical and 
documentary analysis for the period. The establishment of new municipalities aimed to stimulate the development of the countryside promoting administrative decentralization through these federal entities. The process of municipalities emancipation in the 1950s is discussed from the perspective of the colonization of Porto Novo, which served as the basis for the formation of the municipality of Itapiranga. As historiographical foundation we approach the concept of municipality present in several Brazilian constitutions. Then we analyze the emancipation process of the municipality of Itapiranga and the notion of development formulated by the Municipal Commission on Economic Development. The paper concludes by inferring that the emancipation of Itapiranga favored a process of local development expressed in several sectors of that municipality.

Keywords | Administrative decentralization; comparative history; Itapiranga; local development; municipal emancipation; Porto Novo.

JEL-Code | O18; R10; R11.

\section{EMANCIPACIÓN MUNICIPAL Y DESARROLLO LOCAL: EL CASO DE ITAPIRANGA}

\section{Resumen}

El propósito en este artículo es examinar el proceso de emancipación del municipio de Itapiranga, en el extremo Oeste del Estado de Santa Catarina, que se produjo en el año de 1954, por lo tanto, en el contexto histórico del pos-Segunda Guerra. El método utilizado es el de la historia comparada, con base en el análisis bibliográfica y documental respecto de la época. La creación de nuevos municipios buscó estimular el desarrollo del interior del país, promoviendo la descentralización administrativa a través de estas entidades federativas. Los procesos de emancipación de municipios en la década de 1950 son discutidos a partir de la colonización "Porto Novo", que sirvió de base para la formación del municipio de Itapiranga. Como fundamentación historiográfica se aborda la concepción de municipalismo presente en diversas constituciones brasileñas. De allí se analiza el proceso de emancipación del municipio de Itapiranga y la noción de desarrollo que se formó a través de la Comisión Municipal de Desarrollo Económico. Como resultado, el artículo permite inferir que la emancipación de Itapiranga favoreció un proceso de desarrollo local que se expresa en diversos sectores del municipio.

Palabras-clave | Descentralización administrativa; desarrollo local; emancipación municipal; historia comparada; Itapiranga; Porto Novo.

Código JEL | O18; R10; R11.

\section{Introdução}

O objetivo do artigo é o de contextualizar a emancipação do município de Itapiranga, localizado no extremo oeste do Estado de Santa Catarina. A instalação do município, oficializada no ano de 1954, situado na fronteira com a Argentina e o Rio Grande do Sul, é decorrente de uma conjuntura histórica sustentada pela legislação emancipatória brasileira, na concepção da importância dos municípios 
para o desenvolvimento local, do pensamento nacional-desenvolvimentista e da conjuntura socioeconômica regional.

Com a implantação da Constituição Nacional de 1947, o municipalismo passou a ser concebido numa perspectiva de desenvolvimento local. Opondo-se à concepção varguista de centralização administrativa, o município foi visto pela Constituição de 1947 como uma forma das políticas públicas atingirem mais eficazmente o interior do país. Assim, na década de 1950, foram estimulados os processos de emancipação de novos municípios, nos quais se insere o caso de Itapiranga.

O artigo considera como fundo de análise o processo de formação e estruturação da colonização Porto Novo, uma colônia étnica e confessional que foi o território onde se formou o município de Itapiranga. Sustentada pela formação de pequenos lotes coloniais em que se desenvolveu uma agricultura de caráter tradicional e familiar, consideramos que as características desse modelo podem ser consideradas, em conjunto, um dos fatores que resultaram no processo de emancipação do município.

Ilustração 1 - Mapa de Santa Catarina, com destaque para a região de abrangência do município de Itapiranga no ano de 1954

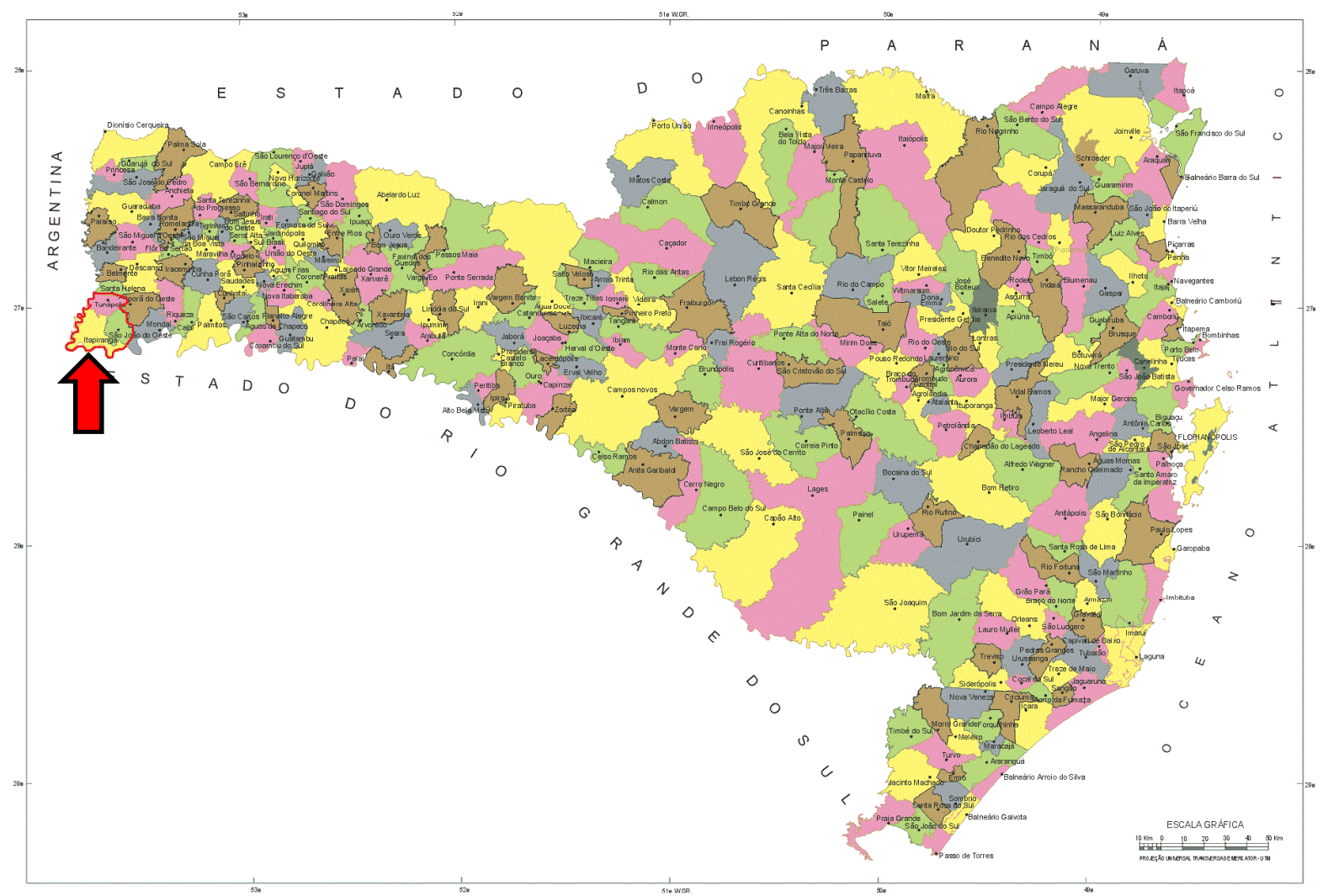


$\mathrm{Na}$ perspectiva da conjuntura nacional, busca-se também analisar o desenvolvimento econômico brasileiro na década de 1950, que, sob o olhar do nacional desenvolvimentismo, disseminou pelo país a noção do subdesenvolvimento e do atraso da economia brasileira. Assim, fomentou-se o discurso de que era necessário promover o progresso e o desenvolvimento do país, inclusive das regiões interioranas. Esse ideal desenvolvimentista atingiu o município de Itapiranga, tendo efeitos diretos na economia e na sociedade regional.

Emancipando-se no ano de 1954, Itapiranga passou a conceber seu projeto de desenvolvimento, implantando políticas públicas, principalmente no quesito infraestrutura. Nesse período é posto em prática também o Plano de Desenvolvimento de Itapiranga, do qual derivou o Relatório de Desenvolvimento Econômico, em 1962, que identificou as deficiências e os projetos necessários para estimular o desenvolvimento do município.

\section{A noção de municipalismo nas Constituições brasileiras}

Ao longo da história do Brasil, os municípios nem sempre foram concebidos como promotores do desenvolvimento regional. Prova disso é a falta de autonomia dos municípios nas diversas Constituições federais brasileiras, sustentada, principalmente, pela centralização do poder na esfera da União. A Constituição de 1824 era um exemplo dessa desconfiança da União frente à gestão dos municípios. Conforme Meirelles (2003, p. 38), naquela Constituição "as municipalidades não passaram de uma divisão territorial, sem influência política e sem autonomia na gestão de seus interesses".

Da mesma forma, apesar de garantir a soberania dos municípios, a Constituição de 1891 não garantiu autonomia municipal no Brasil. Naquele período, destacamos a influência dos coronéis sobre a administração dos municípios, na maioria dos casos, formando nichos de poder político, descomprometidos com o desenvolvimento íntegro dos municípios e de sua população.

Apesar da Constituição de 1937 propor maior prestígio aos municípios, os seus efeitos não puderam ser sentidos de forma efetiva, devido a seu curto período de vigência. Logo no ano de 1937, com o golpe varguista, a Constituição caracterizou-se novamente pela concentração dos poderes no Executivo da União, ferindo a autonomia municipal.

$\mathrm{Na}$ Constituição de 1947 os municípios passaram a ter um reconhecimento maior da União quanto as suas possibilidades administrativas. Ficou, assim, assegurada autonomia política, administrativa e financeira aos municípios, fortalecendo a concepção de que o município poderia ser uma alavanca para o desenvolvimento regional. No entanto, como destaca Felisbino (2011), ainda não se pode falar 
efetivamente de autonomia dos municípios naquele período, pois estavam subordinados às legislações Federais e Estaduais, que, em muitos casos, limitavam a sua capacidade financeira e administrativa. Conforme o autor, somente com a Constituição de 1988 é que se pode falar efetivamente em autonomia política, administrativa e financeira dos municípios, quando lhes foi assegurada a possibilidade de elaborar suas leis orgânicas.

$\mathrm{Na}$ visão de Santin (2007), antes da Constituição de 1988 o município teve reduzida e até extinta sua autonomia e autogovernabilidade, devido a inúmeros fatores históricos e governamentais, tendo um tratamento subalterno, apesar da grande maioria dos textos constitucionais preverem sua autonomia "formal".

A emancipação do município de Itapiranga esteve diretamente ligada a essa conjuntura, principalmente no quesito da discussão do desenvolvimento local. Quando ainda pertencia ao município de Chapecó, o Distrito de Itapiranga esteve praticamente desassistido pelos serviços públicos, o que era compreensível pela grande área de abrangência do município e pela sua limitação financeira. Quando abordaremos a questão da emancipação do município de Itapiranga, perceberemos que isso só foi possível graças a uma emenda à Constituição do Estado de Santa Catarina, representando uma manobra política para contentar diversos segmentos políticos do interior do estado.

\section{A colonização Porto Novo}

O projeto de colonização Porto Novo foi idealizado pela Sociedade União Popular - Volksverein, instituição que coordenou a implantação de outras colônias alemãs no Rio Grande do Sul, vinculada aos Padres Jesuítas, com o objetivo de implantar no extremo-oeste de Santa Catarina uma nova fronteira agrícola e social. O empreendimento foi financiado pela Cooperativa de Crédito Sparkasse e fundado oficialmente no ano de 1926. Já no ano de 1928 a colonização recebeu o nome de Itapiranga, nome dado atualmente ao município, gerando mais tarde a emancipação dos municípios de Tunápolis e São João do Oeste.

A Volksverein für die deutschen Katholiken in Rio Grande do Sul não era necessariamente uma empresa de colonização. Era, na verdade, uma entidade associativa fundada para dar assistência à população de descendência alemã e católica no Sul do Brasil. Essa associação chegou a ter cerca de oito mil associados no período da Primeira Guerra Mundial.

A característica do empreendimento Porto Novo possuía a peculiaridade de aceitar somente migrantes que fossem de origem germânica e católica. As terras nessa colônia foram adquiridas por famílias que buscavam novas fronteiras agrícolas originárias das colônias velhas do Rio Grande do Sul e de Santa Catarina, onde as terras já estavam subdivididas e esgotadas. Da mesma forma, adquiriram 
terras em Porto Novo, imigrantes que fugiam das duras condições de vida em vilarejos europeus, expulsos pelas atrocidades da guerra, pela perseguição étnica e política, ou pelas péssimas condições de vida e de trabalho lá existentes.

Inicialmente a ideia da Sociedade União Popular era a de fundar uma colônia com essas características em solo gaúcho, mas tal empreendimento não foi visto com bons olhos pelo governo do Rio Grande do Sul, além do valor das terras serem muito altos. Outros empreendimentos com estas características já haviam sido postos em prática em solo gaúcho no final do século XIX, como a colonização de Serro Azul (Cerro Largo). Outra iniciativa de colonização de caráter étnico foi a da região de Panambi, na colonização Neu-Württemberg (NEUMANN, 2009).

Buscou-se, também, a compra de um lote de terras em Santa Catarina, pois era de interesse do governo catarinense promover a ocupação daquele espaço, já contestado algumas vezes ao longo da história. O território do contestado, relativo ao oeste do estado de Santa Catarina, passou a receber incentivos governamentais para fomentar sua colonização, garantindo, assim, a ocupação desse espaço através da implantação de colônias escrituradas. Esse território fora contestado pelo estado do Paraná e também pela Argentina, no final do século XIX e no início do $\mathrm{XX}$, surgindo daí o desejo do governo catarinense promover a ocupação organizada e sistematizada através da concessão e da venda de lotes coloniais a empresas interessadas em promover a ocupação territorial, em detrimento de posseiros que viviam nesse espaço.

A colonização Porto Novo foi organizado de forma que fossem vendidos lotes rurais de aproximadamente 25 hectares. Foram organizados também centros comunitários, havendo geralmente a construção de uma capela e de uma escola, onde, em alguns casos, também foram abertas casas comerciais para abastecer as famílias com suprimentos.

A base da economia da colônia nas três primeiras décadas de colonização caracterizou-se pelo aspecto tradicional e pela agricultura familiar. Destaca-se a importância da mão de obra na atividade agrícola, frente à escassez de equipamentos e de tecnologias modernas de produção. Justifica-se, assim, a necessidade da formação de famílias com muitos filhos, necessários para o trabalho na lavoura.

As condições de vida da população, para além das necessidades básicas, eram bem precárias. Havia pouco acesso à informação, condições de higiene precárias e proliferação dos mais variados tipos de doenças, ocasionando uma mortalidade elevada e uma expectativa de vida baixa.

A produção agrícola destinava-se basicamente para o consumo do grupo familiar, sendo o fumo e a banha os únicos produtos de valor comercial capazes de gerar alguma renda. Essa produção mantinha uma rede de comercialização que sustentava as casas comerciais e a classe dos comerciantes, responsáveis por 
comprar a produção dos colonos e por transportá-la para centros de distribuição, bem como fornecer produtos de necessidade básica às famílias da colônia.

De maneira geral, a classe comercial detinha um poder persuasivo sobre os colonos, sustentado pelas relações comerciais entre eles. O comerciante era visto na colonização como um líder comunitário, uma espécie de orientador e instrutor. Isso dava a ele um poder de persuasão em sua área de influência, orientando os colonos sobre os mais variados temas, que iam desde as práticas agrícolas aos assuntos de gestão financeira, e, principalmente, influenciava sua orientação político-partidária. Esse aspecto foi muito decisivo no processo de emancipação de Itapiranga e nas primeiras eleições do município.

Essa realidade de Itapiranga começou a sofrer mudanças a partir da década de 1950, como reflexo do desenvolvimento econômico brasileiro e do sentimento desenvolvimentista instaurado principalmente no governo de Juscelino Kubitschek, o qual disseminou pelo país a modernização da atividade agrícola, no intuito de abastecer os centros urbanos em processo de expansão.

\section{O contexto econômico brasileiro na década de 1950 e o desenvolvimento local}

Terminada a Segunda Guerra Mundial, iniciou-se um processo de readequação e de reestruturação da economia mundial, principalmente no que tange à reconstrução dos países diretamente atingidos pelo conflito e aqueles que sentiram os efeitos colaterais de sua conjuntura. Podemos afirmar que, a partir da segunda metade da década de 1940, e mais intensamente a partir da década de 1950, criaram-se dispositivos de injeção de recursos financeiros para financiamentos de projetos de desenvolvimento dos países, através da criação de instituições financeiras como o Banco Internacional de Reconstrução e Desenvolvimento BIRD e o Fundo Monetário Internacional - FMI.

Grande parte dos países iniciou, a partir daquele período, um processo de expansão da industrialização. Este processo foi orquestrado pelos países com economias solidificadas, principalmente os Estados Unidos da América. Formaram-se nesse período as características da globalização da economia mundial, através de complexos fluxos de exportações e importações, tanto de produtos industrializados, de bens de consumo e de produtos agrícolas, como de bens de capital.

No Brasil, a discussão quanto ao processo de modernização da economia também se tornou amplo a partir da década de 1940, principalmente no que tange ao processo de industrialização. Isso foi possível graças à disponibilidade de bens de capital, que foram utilizados pelo Estado para o financiamento de obras de infraestrutura e implantação de indústrias de produção de bens de consumo. 
Conforme Oliveira (1989, p. 64),

Especialmente entre 1947 e 1954, o Brasil teve a seu favor um ciclo internacional expansivo, paralelamente a uma situação de abundância de reservas internacionais. Através da utilização das grandes reservas acumuladas durante a Guerra, logo nos primeiros anos, o país passou a implementar a segunda etapa da industrialização via substituição de importações, durante a qual foram criadas diversas indústrias. No nosso país, o período que vai de 1945 até aproximadamente 1962 representa uma fase de expansão, muito embora não tenha havido um crescimento estável do PIB, o qual, todavia, apresentou uma taxa média de crescimento da ordem de $6,8 \%$ no período, taxa esta bastante satisfatória se comparada ao desempenho do resto do mundo.

Nesta conjuntura de expansão e modernização da economia nacional, merece destaque a fundação do Banco Nacional de Desenvolvimento - BNDE, no ano de 1952. Esta instituição de fomento, que mais tarde foi denominada Banco Nacional de Desenvolvimento Econômico e Social (BNDES), foi criada com fundos financeiros provindos de uma política de aproximação entre Brasil e Estados Unidos e também com uma modesta disponibilidade de recursos nacionais.

Nos primeiros anos de funcionamento, o BNDES estabeleceu algumas prioridades para alavancar o desenvolvimento industrial brasileiro. Como as deficiências estavam justamente na questão da infraestrutura, os primeiros investimentos foram destinados a aparelhar portos e ferrovias, aumentar a capacidade de armazenamento, criar frigoríficos e matadouros, elevar o potencial elétrico e desenvolver a agricultura e as indústrias de base.

Outra medida adotada pelo BNDES e pelo Estado brasileiro foi firmar parceria com a Comissão Econômica para a América Latina e Caribe, a CEPAL, com o intuito de procederem a análises de conjuntura econômica, buscando direcionar os investimentos para o desenvolvimento econômico brasileiro. Os ideais cepalinos partiram do pressuposto do subdesenvolvimento da América Latina, e propunham que a industrialização apoiada pela ação do Estado seria a forma básica de superação do subdesenvolvimento latino-americano, que, conforme Colistete (2001), preponderou principalmente nas décadas de 1950 e 1960, principalmente até o ano de 1964. Conforme o autor, a diversificação do setor industrial brasileiro constituiria o principal meio de superação da condição de subdesenvolvimento do país.

Um fato que destacamos é a concepção acerca da condição econômica brasileira, concebida a partir da década de 1950 como atrasada, se comparada à de países com uma economia considerada desenvolvida, conforme destaca Cardoso (1993). Essa concepção se arraigou no país, atingindo inclusive a região oeste de Santa Catarina. É a partir da ideia de atraso em relação a uma conjuntura 
macroeconômica que a sociedade regional concebeu a necessidade de promover o desenvolvimento da economia local.

A economia brasileira começou a ser direcionada a partir da década de 1950 para um processo de modernização, principalmente do setor industrial. Incentivou-se a criação de indústrias para a produção de bens de consumo no intuito de desacelerar a política de importação destes produtos para o consumo interno. Tomaram impulsos, a partir de então, indústrias automobilísticas, de eletrodomésticos e de gêneros alimentícios.

Nas décadas de 1950 e 1960 havia preocupação nacional quanto à baixa produtividade da agricultura brasileira, principalmente pela existência de latifúndios e pela permanência de técnicas atrasadas de produção. Em consequência disso, houve necessidade de aumentar a produção agrícola para abastecer centros urbanos desprovidos principalmente de gêneros alimentícios, como milho, feijão, arroz e derivados de carne.

O ideal nacional-desenvolvimentista começou a ganhar força no país com o final da Segunda Guerra Mundial. Na análise de Erbereli Júnior (2012), até mesmo o Partido Comunista Brasileiro manifestava, na década de 1950, preocupação quanto ao atraso da economia brasileira, da necessidade da ampliação do setor industrial e a miséria da população, principalmente das áreas rurais.

Essa nova conjuntura da economia nacional teve reflexos sobre praticamente todo o território brasileiro, seja na expansão da fronteira agrícola e modernização da agricultura, seja na diversificação e ampliação do setor industrial. Em Santa Catarina ocorreu a expansão do setor industrial e a modernização das práticas agrícolas.

Conforme Goularti Filho (2002), no estado de Santa Catarina a década de 1950 é caracterizada pela expansão do setor industrial, principalmente pelo estímulo à produção para o mercado interno, convergindo para a solidificação das agroindústrias catarinenses. Conforme o autor, a partir da década de 1950 já não era mais possível pensar a agricultura isoladamente, pois ela se tornou neste período um ramo da indústria, tanto pela industrialização de derivados da agricultura, quanto pela inserção de equipamentos e de produtos químicos nas propriedades.

Nosso objetivo ao contextualizar a conjuntura econômica brasileira no período do pós-guerra é o de situar, de forma breve, o crescimento econômico percebido a partir daquele período, a fim de compreender de que forma esse desenvolvimento econômico afetou o interior do país, principalmente, a região oeste do estado de Santa Catarina. Temos de ter presente de que a partir da década de 1950 começouse a criar uma nova perspectiva econômica no Brasil, alicerçada principalmente na industrialização. Esse sentimento de prosperidade se espalhou pelo país. 
A comunidade regional de Itapiranga, diante das adversidades da agricultura tradicional, percebeu a necessidade de pensar um projeto de desenvolvimento para a região. Essa ideia foi influenciada pela conjuntura econômica nacional e catarinense, que, frente à demanda por produtos de origem agrícola para abastecer os centros urbanos e as linhas de financiamento para o setor, incentivou a produção local para abastecimento do mercado interno em expansão.

\section{A emancipação do município de Itapiranga}

Até a década de 1950, o extremo oeste do estado de Santa Catarina pertencia ao município de Chapecó, que englobava grande parte da região oeste do estado. A criação do município de Chapecó está vinculada à questão de fronteiras entre Argentina e Brasil e, também, entre Paraná e Santa Catarina. Para efetuar a ocupação ordenada do espaço, foi criado, no ano de 1917, o município de Chapecó.

Como a área territorial do município de Chapecó era muito extensa, era evidente que grande parte da região ficou desassistida em termos de assistência e infraestrutura. Até por volta da década de 1950, as ações do governo estadual e da municipalidade de Chapecó foram muito tímidas na região de Itapiranga. A população somente pôde participar da votação para vereador e prefeito no ano de 1947, quando foram disponibilizadas urnas nas comunidades com maior número de habitantes. Isso foi possível graças à Constituição Nacional de 1946, que previu maior autonomia administrativa e financeira aos municípios brasileiros, garantindo a eleição para prefeitos e vereadores (MEIRELLES, 2003).

De maneira geral, era a colonizadora Volksverein que tratava de implantar as obras de infraestrutura necessárias para a região, como estradas, escolas e assistência médica. O município de Chapecó, por exemplo, trabalhou na melhoria de uma estrada em Itapiranga somente no ano de 1951, a primeira vez em que um trator da prefeitura prestou serviços na região.

O governo de Santa Catarina muito pouco fez em prol da região extremo oeste nas primeiras três décadas da colonização, a não ser conceder os direitos de compra e venda de terras a empresas colonizadoras, conforme destaca Werle (2011). No ano de 1929 houve visita à região do então governador Adolfo Konder Reis, que viajou pelo extremo oeste com uma comitiva de cerca de 30 autoridades e 20 cargueiros, no intuito de reconhecer o espaço e as condições de vida da população (D’EÇA, 1991). De prático, a passagem do governador resultou na troca dos nomes das localidades de Porto Feliz para Mondaí e de Porto Novo para Itapiranga.

De notório, na década de 1930, temos de destacar a criação do Distrito de Itapiranga, criado pelo Decreto $\mathrm{n}^{\circ} 213$, de 24 de Fevereiro de 1932, sendo o $13^{\circ}$ 
Distrito do município de Chapecó. Com isso, foi criada uma estrutura administrativa em Itapiranga representada pelos cargos de Subintendente, secretário e telegrafista, escrivão, juiz de paz, delegado de polícia, inspetor de polícia e coletor (ROHDE, 2011, p. 171). Na prática, a criação do Distrito representou apenas a criação de cargos administrativos indicados por autoridades superiores, no intuito, principalmente, de zelar pela segurança e de aplicar a coleta de impostos.

Diante da falta de assistência do município de Chapecó à região, lideranças de Itapiranga iniciaram o debate quanto ao processo de emancipação. A dificuldade inicial nesse processo foi justamente a legislação estadual. A então Constituição Estadual de Santa Catarina regia que a emancipação de novos municípios seria viabilizada apenas se na localidade residissem pelo menos 20 mil habitantes e esta obtivesse arrecadação anual de 300 mil cruzeiros.

Como o número de habitantes era inferior ao estabelecido constitucionalmente, cerca de 10 mil habitantes no ano de 1947 (ROHDE, 2011), a solução seria criar um município maior, englobando diversas localidades. Essa discussão foi intensa na região, principalmente pelo fato de que as lideranças regionais sentiam a necessidade de dividir o grande município de Chapecó. No ano de 1953, Santa Catarina criou a Emenda Lenoir Vargas Ferreira à Constituição estadual, que facilitava a criação de novos municípios, emancipados da sede, Chapecó, pela Lei $n^{\circ} 133$, de 30 de dezembro de 1953, oito municípios: São Miguel do Oeste, São Carlos, Mondaí, Palmitos, Dionísio Cerqueira, Xaxim, Xanxerê e Itapiranga.

Em fragmento da tese de doutoramento de Eidt (2009, p. 234), podemos perceber no personagem Arthur o sentimento de desassistência da população local em relação ao município de Chapecó:

Arthur, mesmo com saúde fragilizada, juntou forças e se envolveu no ardente desejo emancipatório da colônia, no final do ano de 1953. Apontava razões fortes para sustentar sua posição. Para ele, a colônia deveria dar um basta à subserviência dócil que estava submetida. Já haviam se passado mais de duas décadas de atrelamento ao município de Chapecó, para o qual somente remetia impostos que, uma vez nos cofres públicos, se transformavam em nada.

A instalação do município de Itapiranga ocorreu no dia 14 de Fevereiro de 1954, e a solenidade ficou ao encargo dos padres vigários de Itapiranga. Conforme Jungblut (2000, p. 197), "a festa foi sublime, com momentos de forte emoção. O Padre Afonso Hansen conseguiu fazer brotar lágrimas de diversas pessoas pelo teor emocionante da sua oratória, além dos repetidos vivas, espocar de foguetes e outros recursos artísticos empregados." 
A comoção da população presente, descrita nesse fragmento, pode ser compreendida pelo sentimento de desamparo da população local frente às adversidades econômicas e sociais encontradas na região na década de 1950 . A emancipação do município de Itapiranga representou, na época, uma perspectiva de desenvolvimento e de progresso, tanto é que as autoridades religiosas empenharam-se nesse acontecimento.

Os efeitos imediatos da emancipação do município de Itapiranga puderam ser sentidos através da aquisição de maquinários para manutenção e abertura de estradas que ligassem a região a centros maiores, favorecendo o deslocamento de pessoas e de produtos para comercialização.

O primeiro governo municipal foi nomeado de forma temporária, com o consenso de políticos e religiosos. No entanto, a campanha para a primeira eleição, ocorrida em outubro de 1954, foi bastante acirrada, revelando as rivalidades políticas presentes historicamente no município de Itapiranga. Essa rivalidade era alimentada principalmente pela oposição entre famílias de comerciantes da sede do município, e também do interior, sustentada por intrigas criadas pela rivalidade ideológica e pela disputa de espaço e influência das casas comerciais. É importante destacar que as lideranças políticas que brigavam pela hegemonia no poder de Itapiranga possuíam fortes vínculos com o Governo Estadual, e isso ficou ainda mais evidente no período do Regime Militar, com a nomeação dos prefeitos municipais.

Apesar da emancipação do município de Itapiranga ter representado uma esperança de prosperidade, a infraestrutura do município era, ainda, bastante precária, e isso dificultava o escoamento da produção e a modernização das propriedades agrícolas. No final da década de 1950, a problemática da saúde atingia boa parte da população, principalmente devido às questões sanitárias, como tratamento de água e esgoto, falta de higiene e assistência à saúde.

No quesito educação praticamente todas as comunidades possuíam escolas e a frequência era estimulada nas famílias, no entanto, a qualidade da educação era questionável (JUNGBLUT, 2000; EIDT, 2009). A necessidade de qualificação dos professores que atuavam nas escolas da região era evidente, resquício ainda do período das escolas comunitárias de caráter paroquial.

Em termos de infraestrutura, Itapiranga apresentava as suas maiores deficiências. As estradas, praticamente todas elas abertas de forma braçal, eram péssimas e cheias de atoleiros, sendo algumas ainda interditadas quando havia a ocorrência de chuva. Conforme Jungblut (2000, p. 209), "faltavam pontes em quase todas as vias fluviais, os veículos pequenos "morriam” dentro da água, os bois sofriam puxando os veículos atolados”. No final da década de 1950 havia um imposto denominado Taxa de Conservação, que era cobrado com base no tamanho da propriedade do agricultor, sendo que cada agricultor era obrigado a trabalhar seis dias por ano de 
forma gratuita, na construção e na manutenção de estradas, denominado em alemão de Wegsteuer.

Conforme Jungblut (2000, p. 210),

A economia se mostrava preocupante, pela falta de indústrias; pela grande concentração da economia na criação de porcos - cerca de 73\% da renda das famílias provinha dos suínos; pela numerosa saída das famílias para o Oeste do Paraná; pela baixa produtividade agrícola; pela pobreza da população; pela pouca tecnologia na agropecuária; pela infraestrutura paupérrima das propriedades e carência de estradas, entre outros aspectos. As pessoas de visão da época vivam aflitas pelo que poderia vir a acontecer se não fossem tomadas providências.

Fato que merece destaque, e que foi determinante para o desenvolvimento de Itapiranga, foi a implantação da energia elétrica no município. Não haveria possibilidade de desenvolvimento do setor industrial sem esse recurso energético. A energia elétrica foi instalada no ano de 1957, trazida de Tenente Portela no Rio Grande do Sul, a uma distância de aproximadamente 30 quilômetros. Para isso, a Prefeitura Municipal buscou o apoio da população, a qual comprou apólices para financiar a obra. Da mesma forma, eram organizados mutirões de voluntários que trabalharam gratuitamente na construção da rede de energia elétrica até Itapiranga.

Percebemos que com a emancipação de Itapiranga fortaleceu-se o discurso da necessidade de desenvolvimento e de progresso para o município. Em artigo publicado no Jornal Clarinadas, edição de 15 de Junho de 1958, vemos o apelo de Guido Schwengber no sentido de promover urgentemente a industrialização e a modernização da agricultura de Itapiranga. Trechos do texto nos dão uma compreensão melhor da análise feita pelo autor no período:

É preciso tirar nossa cidade da redoma que a asfixia e isola do resto do mundo, retendo-nos na realidade que já deveria ser antiquada na época de nossos bisavós. Somos pela industrialização de Itapiranga, pela modernização de seus métodos agrícolas, pela atualização do pensamento que norteia nosso povo. Não nos parece justo que quando o mundo já se prepara para viagens siderais nós ainda vivamos à maneira do século passado. E quando todo o Brasil sabe que a queima das matas é prejudicial à terra, em Itapiranga se preparam as roças com fogo [...] No momento em que o mundo atingiu o quarto período de sua evolução agrícola nós ainda estamos no segundo, qual seja o do emprego da enxada como principal objeto de trabalho do nosso lavoureiro (ITAPIRANGA, 1958, p. 5). 
Percebemos que o autor do artigo é enfático ao confirmar o atraso da economia. Ao afirmar que é preciso retirar Itapiranga de uma redoma, o autor apela para o fim das barreiras que atrasam a economia local. Como solução para o problema, o artigo aponta algumas alternativas:

\begin{abstract}
Naturalmente o colono deverá colaborar. Ele não pode persistir teimosamente na afirmativa de que seu avô, usando os métodos que ele está empregando, foi muito bem, e estribado nisso, negar-se a adotar sistemas e processos modernos. É necessário convencê-los disso, principalmente a nova geração. A nossa indústria, se é que já podemos considerar tal, é a mesma que a Europa viu há duzentos anos atrás, na época obsoleta dos burgos, ou quiçá, já nos feudos. [...] O que não há é iniciativa, é coragem para um empreendimento de envergadura. A industrialização de suínos, cuja criação seria ainda mais incentivada e aumentada com a instalação de um moderno frigorífico é uma necessidade que se impõem (ITAPIRANGA, 1958, p. 5).
\end{abstract}

Em outra reportagem publicada em jornal local, percebemos um depoimento da necessidade do povo itapiranguense pensar o futuro da região, numa referência a Comissão Municipal de Desenvolvimento Econômico como entidade representativa responsável por planejar as ações socioeconômicas necessárias para o progresso de Itapiranga:

Itapiranga tem um futuro à vista, que os itapiranguenses desconhecem. Nos últimos 4 anos como o pensamento do povo tem mudado! Que será quando em breve as casas tiverem televisão? [...] O progresso em Itapiranga virá, ou da parte do povo para o povo, ou de gente de fora para outros. Se quereis um bom futuro para vossos filhos, não criticai o que se está realizando agora, pois se não olharmos 10 anos para frente, chegaremos 100 anos atrasados (ITAPIRANGA, 1962, p. 1).

No fragmento acima, percebemos o apelo quanto a urgência da população em abraçar a ideia do desenvolvimento e do progresso para Itapiranga. Temos de ter presente que a partir da emancipação de Itapiranga, mas mais precisamente a partir do final da década de 1950, criou-se uma atmosfera de um ideal de progresso para Itapiranga.

Em artigo de autoria de Vitor Reis, publicado no Jornal Oeste em Marcha de 1963, percebemos mais um apelo ao povo de Itapiranga quanto a necessidade de progredir até mesmo com a construção de uma sociedade recreativa, a exemplo de um frigorífico que estava em fase de construção: 
Nesta etapa em que podemos acreditar na construção de um moderníssimo frigorífico em Itapiranga, que terá tudo de moderno, até o grito do porco será sufocado em nossa exemplar indústria por um choque elétrico. Nesta época em que queremos dar nosso brado de independência econômica. Nesta encruzilhada em que ou progredimos ou retrocedemos. Justamente nesta situação em que nos encontramos, é a última hora de construirmos algo que nos represente. Esta hora é a de construirmos a nossa Sociedade com S maiúsculo. [...] Avante. Não vacile. Para a frente! (ITAPIRANGA, 1963, p. 1).

As perguntas que cabem são: como a população reagia ao ler os jornais, ouvir ao rádio ou conversar com lideranças sobre a necessidade da modernização da economia, principalmente, da agricultura, principal atividade econômica do município? Como a população concebeu esse ideal de progresso idealizado naquele período? A emancipação do município de Itapiranga fez-se sentir nas pessoas do interior? Quem foram as lideranças que constataram um possível atraso da economia e estimularam o progresso do município?

No fragmento acima, o autor também fala de uma encruzilhada, em que Itapiranga deveria escolher entre progredir ou retroceder. Mas, o que representava, naquele período, progredir ou retroceder? Será que esse não era um questionamento feito unicamente por determinadas pessoas ou classes sociais diretamente interessadas na modernização da economia local? Será que a população estava realmente consciente de sua condição? Ela se concebia como atrasada? As práticas agrícolas, por exemplo, eram atrasadas na visão dos colonos? Qual era a referência para a construção da noção de atraso?

A imprensa regional foi bastante incisiva nesse discurso. Mas, de que forma, e com que intensidade, ela atingiu a população itapiranguense? Esse é um questionamento que precisa ser levantado para que não generalizemos a ideia de que o ideal de desenvolvimento e progresso que se alastrava, impulsionado, principalmente, pela expansão da economia brasileira e catarinense no período, nasceu de forma espontânea em toda a sociedade itapiranguense.

$\mathrm{Na}$ década de 1950 a conjuntura da colonização de Itapiranga já apresentava mudanças substanciais que projetavam o sentimento de que era necessário repensar algumas práticas. O momento histórico era outro, já não havia aquela preocupação de derrubar a mata, de estruturar a propriedade, das crianças pequenas que precisavam ser cuidadas, deixando de lado o trabalho na atividade agrícola. A maioria das famílias que se instalaram nos primeiros trinta anos de colonização tinham condições, na década de 1950, de aumentar a produção e, principalmente, aumentar a comercialização de seus produtos. Muitos filhos já estavam na idade do trabalho e as novas famílias que se instalavam com a segunda leva de migrantes, que compraram lotes após a Segunda Guerra Mundial, também 
os apresentavam aptos ao trabalho da roça. A colônia começou a aspirar novas perspectivas sob aquela nova conjuntura.

\section{Comissão Municipal de Desenvolvimento Econômico de Itapiranga}

Diante da condição do município de Itapiranga, contextualizada anteriormente, lideranças locais iniciaram discussões para buscar alternativas econômicas e sociais para promover o desenvolvimento de Itapiranga. Em 1962 se formou a Comissão Municipal de Desenvolvimento Econômico de Itapiranga (Comude), caracterizando-se como uma composição de lideranças regionais "com os objetivos de promover, coordenar e controlar a execução das sugestões do plano de desenvolvimento econômico para Itapiranga, assim como de manter vivo e atuante o espírito desenvolvimentista da população.” (HAHN, 2005, p. 65).

A Comissão Municipal de Desenvolvimento Econômico era a entidade representativa dos diversos segmentos da sociedade: indústria, comércio, agricultura e administração pública. A Comude nasceu basicamente como consequência do Plano Econômico idealizado pela Administração Municipal de Itapiranga no ano de 1960. A Comissão reunia-se regularmente para discutir ações de desenvolvimento econômico e social, tendo contato direto com agências de fomento e lideranças políticas estaduais. As medidas tomadas visando o desenvolvimento da região de Itapiranga a partir da década de 1960 foram praticamente todas elas idealizadas pela Comude. Era função da comissão decidir quais eram os setores estratégicos ou deficientes que necessitavam de investimentos, e, acima de tudo, estimular a sociedade regional a participar ativamente da execução dos projetos que seriam postos em prática.

$\mathrm{Na}$ ata da reunião da Comissão Municipal de Desenvolvimento Econômico, datada de 30 de outubro de 1963, está registrada a vinda de um veterinário da Alemanha Ocidental para trabalhar em Itapiranga. $\mathrm{Na}$ mesma ata, foram discutidos assuntos referentes aos auxílios financeiros destinados à Cooperativa Laticínios Itapiranga e também foi abordada a necessidade de melhoria da estrutura telefônica do município de Itapiranga (OESTE EM MARCHA, 1963, p. 1).

No entanto, é preciso ter claro que a Comissão Municipal de Desenvolvimento Econômico surgiu também por uma exigência da instituição alemã Misereor, que foi grande incentivadora e financiadora dos projetos de desenvolvimento de Itapiranga. Os membros da Comude conheciam os setores de maior deficiência na economia regional, tendo um contato direto com os diversos segmentos da sociedade, pois se tratava de uma entidade representativa. Como podemos perceber em fragmento de jornal local do ano de 1962, a Comude atuava em diversos segmentos da economia: 
A Comissão Municipal de Desenvolvimento, pelo seu secretário geral, nos informa que na segunda quinzena de setembro virão técnicos da firma Pearson, para dar combate à verminose em nosso município. Farão 35 a 40 demonstrações gratuitas, ou seja, mais ou menos uma em cada linha. É mais um empreendimento resultante do Planejamento feito por técnicos para o nosso município. Pedimos, pois, que os colonos se interessem para que possamos eliminar esta doença entre nossas criações (INFORMA, 1962, p. 1).

Sobre a questão da construção de um frigorífico, por exemplo, as lideranças locais, principalmente da classe empresarial, já sentiam no final da década de 1950 a necessidade ou a possibilidade de construí-lo em Itapiranga. Era uma questão que parecia bastante óbvia na época, se analisarmos a logística de engorda e abate de suínos, pois a região era uma grande produtora de suinocultura e a grande maioria dessa produção era levada para frigoríficos distantes para ser abatida.

Em artigo assinado por Heinrich Lenz, percebemos o debate da sociedade regional acerca da necessidade de se construir um frigorífico no município. Intitulado "Wir bauen unser Schlachthaus" - ou: "Nós construiremos nosso frigorífico" -, o autor relata uma reunião realizada com a presença de lideranças regionais, clamando para a comunidade regional esquecer as desavenças do passado e se unir nesse projeto que, segundo ele, era um desejo antigo da região (WIR BAUEN, 1961, p. 4).

Sobre o papel da Comissão Municipal de Desenvolvimento Econômico, é preciso ter ciência de que seus membros representavam esferas da sociedade itapiranguense. Será que os componentes da Comude tinham consciência de seu papel na discussão do futuro da região? Quais interesses representavam? Interesses coletivos? De determinadas classes ou dos poderes itapiranguenses? Não seriam eles influenciados por interesses de terceiros? As decisões tomadas pela Comude, certamente, sofreram influência de pessoas que tinham interesses econômicos associados ao desenvolvimento de Itapiranga. Os setores que receberam investimentos foram favorecidos pela Comissão Municipal de Desenvolvimento Econômico. Não se podem julgar decisões tomadas no passado e o reflexo que tiveram na sociedade. Mas, é possível analisa-las pela perspectiva de que os membros da referida comissão não agiam, simplesmente, de forma altruística: eles representavam os interesses de classes sociais às quais deviam comprometimento.

No ano de 1962, a Comissão Municipal de Desenvolvimento Econômico ficou responsável por administrar recursos no montante de 25 mil marcos, enviados pelo Instituto Misereor, da Alemanha Ocidental, e depositados nos cofres da Caixa Rural de Itapiranga. Esse recurso era destinado a empreender pequenos projetos junto aos agricultores. 


\section{Considerações Finais}

O objetivo do texto foi analisar o processo de emancipação do município de Itapiranga no contexto do desenvolvimento brasileiro após a Segunda Guerra Mundial. Com base em análises bibliográficas e documentais, podemos concluir que o processo emancipatório, que esteve alicerçado no discurso e na perspectiva de desenvolver a região, esteve condicionado a uma constituição favorável e à relação de influência política partidária de lideranças locais com deputados catarinenses que aprovaram a emancipação de diversos municípios na década de 1950.

A emancipação do município de Itapiranga é resultado de uma conjuntura histórica decorrente da realidade brasileira após a Segunda Guerra Mundial. Naquele período, instaurou-se no país o ideal do nacional-desenvolvimentismo, que disseminou pelo país a noção de desenvolvimento e de progresso, principalmente no aspecto econômico.

Os municípios ganharam importância como ferramentas de descentralização administrativa. A emancipação do município de Itapiranga está vinculada a essa conjuntura, que, por intermédio da Constituição Nacional de 1947 e das emendas constitucionais do estado de Santa Catarina, conseguiu sua emancipação no ano de 1954.

A partir da década de 1950, o cenário econômico brasileiro propiciou com maior intensidade - não que anteriormente não fosse possível - o desenvolvimento das regiões interioranas. Assim, a descentralização administrativa, com uma valorização maior das entidades federativas municipais, representou uma possibilidade para o desenvolvimento regional. Temos de ressaltar que as emancipações municipais cresceram consideravelmente em diversas regiões do Brasil a partir da década de 1950, facilitados pela legislação propícia para tal.

Nesse contexto, devemos ter presente também a colonização de Itapiranga, fundada no ano de $1926 \mathrm{com}$ a denominação de Porto Novo e que foi idealizada para receber famílias de colonos que se instalaram em propriedades agrícolas de pequeno porte. As condições de vida e de trabalho destas famílias foram um fator propício para justificar os discursos oficiais de que era necessário promover o desenvolvimento local, estimulando a infraestrutura e gerando condições de melhoramento da realidade então vivida no interior de Itapiranga.

Apesar da situação financeira deficitária, o município de Itapiranga passou a centralizar seus esforços na ampliação da infraestrutura básica para o desenvolvimento do município. Através do Plano de Desenvolvimento Econômico e da elaboração do Relatório de Desenvolvimento Econômico, o município buscou elencar suas deficiências e traçar metas e objetivos para o desenvolvimento local. Diante da falta de atendimento que o município de 
Chapecó dispensava à Itapiranga, a sua emancipação foi fundamental para o desenvolvimento da região, haja visto ter possibilitado a melhoria de sua infraestrutura, trazendo de forma quase imediata resultados às áreas de energia elétrica e de telefonia, além da abertura e manutenção de estradas.

\section{Referências}

CARDOSO, Fernando Henrique. As ideias e seu lugar: ensaios sobre as teorias do desenvolvimento. Petrópolis (RJ): Vozes, 1993.

COLISTETE, Renato Perim. O desenvolvimentismo cepalino: problemas teóricos e influências no Brasil. Estudos avançados, São Paulo, v. 15, n. 41, Jan./ Abr., 2001.

D’EÇA, Othon Gama. Aos espanhóis confinantes. 2. ed. Florianópolis: FCC; Fundação Banco do Brasil; Editora da UFSC, 1991.

EIDT, Paulino. Os sinos se dobram por Alfredo. Chapecó: Argos, 2009.

ERBERELI JÚNIOR, Otávio. O debate em torno da questão agrária (1950-1960): o PCB e Caio Prado Júnior. Em tempo de histórias, Brasília, n. 21, p. 137-161, Ago./Dez., 2012.

FELISBINO, Riberti de Almeida. Os municípios brasileiros nas Constituições Federais, 1824 a 1988. Evocati Revista, n. 63, 2011. Disponível em $<$ http://www.evocati.com.br/evocati/artigos.wsp?tmp_codartigo $=471>$. Acesso em: 08 jul. 2013.

GOULARTI FILHO, Alcides. Formação econômica de Santa Catarina. Florianópolis: Cidade Futura, 2002.

HAHN, Mauro. Capital Social e estratégias de desenvolvimento econômico na microrregião de Itapiranga (SC). 2005. 121 f. Dissertação (Mestrado em Agroecossistemas) - Programa de Pós-Graduação em Agrossistemas, Universidade Federal de Santa Catarina, Florianópolis, 2005.

INFORMA a Comude. Itapiranga em Marcha, Itapiranga, 31 de Agosto, n. 76, p. $1,1962$.

ITAPIRANGA e o desenvolvimento agrícola. Clarinadas, Itapiranga, 15 de Junho, n. 6, p. 5, 1958. 
ITAPIRANGA vive uma encruzilhada histórica. Itapiranga em Marcha, Itapiranga, 30 de Novembro, n. 82, p. 1, 1962.

ITAPIRANGA constrói a sua sociedade. Oeste em Marcha, Itapiranga, 22 de Junho, n. 101, p. 1, 1963.

JUNGBLUT, Roque. Documentário Histórico de Porto Novo. São Miguel do Oeste: Arco Iris Gráfica e Editora, 2000.

MEIRELLES, Hely Lopes. Direito Municipal Brasileiro. 13. ed. São Paulo: Malheiros Editores, 2003.

NEUMANN, Rosane Márcia. Uma Alemanha em miniatura: o projeto de imigração e colonização étnico particular da colonizadora Meyer no Noroeste do Rio Grande do Sul (1897-1932). (Tese) Doutorado em História. Programa de PósGraduação em História da Pontifícia Universidade Católica do Rio Grande do Sul, Porto Alegre, 2009.

OESTE EM MARCHA, Jornal. 18 de Novembro, Itapiranga, n. 122, p. 1, 1963.

OLIVEIRA, Vera Beatriz da Silva. Os ciclos da economia brasileira. Revista Análise Econômica, Porto Alegre, ano 7, n. 11, p. 63-90, 1989.

ROHDE, Maria W. Espírito Pioneiro: a herança dos antepassados. Itapiranga: Gráfica e Editora Porto Novo, 2011.

SANTIN, Janaína Rigo. O tratamento histórico do poder local no Brasil e a gestão democrática municipal. In: Seminário Nacional Movimentos Sociais, Participação e Democracia, 2., 2007, Florianópolis. Anais... Florianópolis (SC): NPMS/UFSC, 2007. Disponível em: <http://www.cfh.ufsc.br/ npms/arquivos/anais_ seminario_npms.pdf $>$. Acesso em 08 jul. 2013.

WERLE, André Carlos. Porto Novo: o reino jesuítico germânico no oeste de Santa Catarina. Curitiba: CRV, 2011.

WIR BAUEN unser Schlachthaus. Itapiranga em Marcha, Itapiranga, 31 de Agosto, n. 52, p. 4, 1961. 
Endereço para correspondência:

Paulo Ricardo Bavaresco - paulo.bavaresco@unoesc.edu.br Rua Oiapoc, 211, Bairro Agostini 89900-000 São Miguel do Oeste/SC, Brasil

Douglas Orestes Franæen-douglas_franzen@yahoo.com.br UPF, Campus I, BR 285, Bairro São José 99052-900 Passo Fundo/RS, Brasil

Tiones Ediel Franzen - tionesf@yahoo.com.br Av. Peter Henry Rolfs, s/n, Campus Universitário 36570-000 Viçosa/MG, Brasil 